\title{
Определение концентрации водорода по фотоэдс МДП структур Pd-оксид-InP
}

\author{
(C) Е.А. Гребенщикова ${ }^{1}$, Х.М. Салихов ${ }^{2}$, В.Г. Сидоров ${ }^{3}$, В.А. Шутаев ${ }^{1}$, Ю.П. Яковлев ${ }^{1}$ \\ ${ }^{1}$ Физико-технический институт им. А.Ф. Иоффе Российской академии наук, \\ 194021 Санкт-Петербург, Россия \\ ${ }^{2}$ Институт прикладных исследований Академии наук Республики Татарстан, \\ 420111 Казань, Россия \\ ${ }^{3}$ ООО „АИБИ“, \\ 194021 Санкт-Петербург, Россия \\ E-mail: eagr.iropt7@mail.ioffe.ru
}

(Получена 28 февраля 2018 г. Принята к печати 12 марта 2018 г.)

\begin{abstract}
Исследована фотоэдс структур металл-диэлектрик-полупроводник ( $\mathrm{Pd} /$ анодный оксид/InP) в зависимости от концентрации водорода в азотно-водородной газовой смеси в интервале $0.1-100$ об\%. Показано,что при одновременном воздействии на структуру освещения и водорода скорость спада фотоэдс структуры $\mathrm{Pd}-$ оксид-InP и концентрация водорода связаны между собой экспоненциально: $N_{\mathrm{H}}=a \exp (b S)$,где $N_{\mathrm{H}}-$ концентрация водорода в газовой смеси в объемных $\%, S=d U /\left.d t\right|_{t=0}-$ скорость изменения сигнала $U$ на начальном участке спада фотоэдс, начиная с момента контакта структуры с газовой смесью, $a$ и $b-$ постоянные, зависящие от толщины слоя палладия и слоя анодной оксидной пленки на InP.
\end{abstract}

DOI: $10.21883 /$ FTP.2018.10.46458.8854

\section{1. Введение}

Водород является чистым и эффективным энергоносителем. В отличие от углеводородного топлива, загрязняющего окружающую среду выбросами вредных отходов, побочный продукт сжигания водорода - только безвредная для окружающей среды вода. Смесь водорода с воздухом взрывоопасна, поэтому при хранении и транспортировке водорода, а также при эксплуатации водородных энергоустановок безопасность использования водорода в качестве энергоносителя дожна определяться эффективными средствами контроля содержания водорода в окружающей среде. В качестве сенсоров водорода предложен ряд устройств, в основу работы которых положены различные физические явления. Принцип действия большинства датчиков водорода основан на регистрации изменений их электрических характеристик в присутствии водорода [1-4]. В работе [5] предложен эффективный способ регистрации наличия водорода в газовой смеси по фотоэдс структур $\mathrm{Pd}-n-\mathrm{InP}$, но данный способ не позволяет количественно определять концентрацию водорода. В работе [6] представлены результаты комплексных исследований влияния водорода на электрические и фотоэлектрические свойства структур с палладиевым контактом, созданных на эпитаксиальных слояx InAs, InP и InAsSbP, при этом показано важное для практических применений значительное преимущество использования фотоэлектрических характеристик для регистрации присутствия водорода в окружающей среде.

В работах [7,8] нами были исследованы электрические и фотоэлектрические характеристики структуры $\mathrm{Pd}-$ оксид $-n$-InP в атмосфере $100 \%$ водорода и без него при освещении структуры со стороны слоя палладия.
Настоящая работа является продолжением начатых исследований.

Цель работы - исследование влияния концентрации водорода в газовой смеси на фотоэдс МДП (металл-диэлектрик-полупроводник) структур на основе $\mathrm{Pd}-$ оксид $-n$-InP.

\section{2. Эксперимент}

Исследуемые структуры изготавливались на подложках $n-\operatorname{InP}(100)$ с концентрацией электронов $10^{16} \mathrm{~cm}^{-3}$ по методике, изложенной в работе [8]. На предварительно очищенной поверхности подложки выращивался слой анодного оксида InP толщиной 100 нм [9]. На его поверхности методом термического напыления в вакууме формировался слой Pd толщиной 25-40нм и контактный слой $\mathrm{Au}$ в форме креста для обеспечения более равномерного растекания тока по поверхности структуры. Активная область площадью $1 \mathrm{Mм}^{2}$, состоящая из слоев $\mathrm{Pd}$ и оксида, ограничивалась по периметру слоем $\mathrm{Si}_{3} \mathrm{~N}_{4}$ для снижения токов утечки. На обратной стороне подложки формировался омический контакт $\mathrm{Cr} / \mathrm{AuGe} / \mathrm{Au}$. Чипы изготовленной таким способом МДП структуры размером $1.4 \times 1.7 \mathrm{Mм}$ монтировались для дальнейших исследований на стандартном кристаллодержателе ТО-18.

Электрические и фотоэлектрические свойства структур исследованы в воздушной среде без водорода и в газовой смеси, содержащей водород. При этом использовались стандартные азото-водородные смеси газов с содержанием водорода $0.1,1.0,3.95,10$ и 100 об\%.

Вольт-амперные характеристики (ВАХ) структур $\mathrm{Pd}-$ оксид- $n$-InP измерялись в интервале температур 


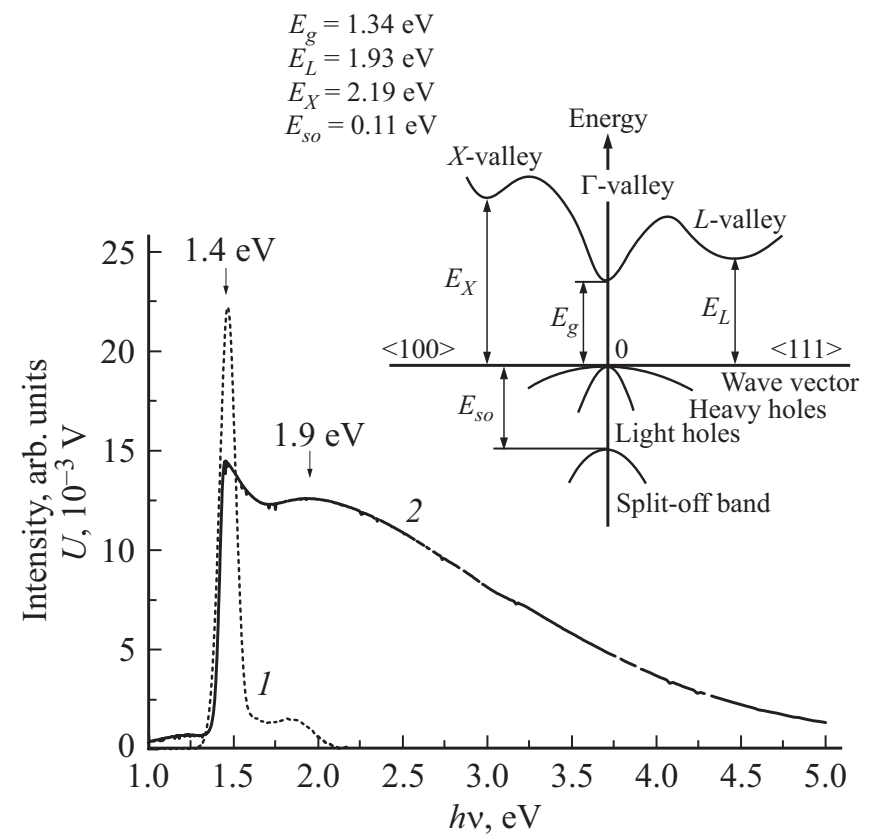

Pис. 1. Спектр излучения светодиода $(1)$ и спектр фоточувствительности (фотоэдс $U$ ) структуры Pd-оксид-n-InP (2). На вставке - зонная диаграмма InP.

90-340 K, а фотоэлектрические - при комнатной температуре. При измерении фотоэлектрических характеристик структур в качестве источника освещения использовался светодиод с энергией $(h v)$ максимума излучения, расположенной в области фоточувствительности структур (рис. 1). Максимум фоточувствительности структур соответствует ширине запрещенной зоны InP в Г-долине (см. вставку на рис. 1). Второй максимум в спектре соответствует ширине запрещенной зоны InP в $L$-долине.

При измерениях электрических и фотоэлектрических характеристик структур $\mathrm{Pd}-$ оксид-n-InP использовались следующие приборы: KEITLEY-2600A (Keithley Instruments, Inc.), синхронный детектор Stanford Research System SR-870, монохроматор МДР-2. Все данные выводились на компьютер. Температурные зависимости BAX измерялись при плавном изменении температуры. Поскольку полная ВАХ (прямая и обратная ветви) записывалась за $3 \mathrm{c}$, а температура образца в течение этого времени изменялась только на $0.3 \mathrm{~K}$, то вносимые погрешности были в пределах погрешности измерения тока. Скорость записи данных при измерении фотоэдс составляла 17 значений/с.

\section{3. Результаты и их анализ}

Анализ ВАХ структур показал, что анодный оксид InP в структуре ведет себя во всем интервале температур как омическое сопротивление [8]. Проводимость потенциального барьера, образующегося на границе оксид $-n$-InP, имеет туннельный или термотуннельный характер. При температурах ниже $200-250 \mathrm{~K}$, как правило, наблюдается два механизма проводимости туннельный при малых напряжениях на структуре и термотуннельный при больших смещениях. При повышении температуры термотуннельный механизм становится преобладающим при всех прямых смещениях на структуре. В присутствии водорода проводимость структур при всех напряжениях и температурах смещается в сторону преобладания туннельного механизма.

На созданных структурах измерялась фотоэдс в воздушной среде без водорода и в газовой смеси, содержащей водород. На рис. 2 представлены зависимости фотоэдс $U$ от времени $t$ для типичной структуры $\mathrm{Pd}-$ оксид $-n$-InP при подаче на структуру газовой смеси с различным содержанием водорода. Эксперимент

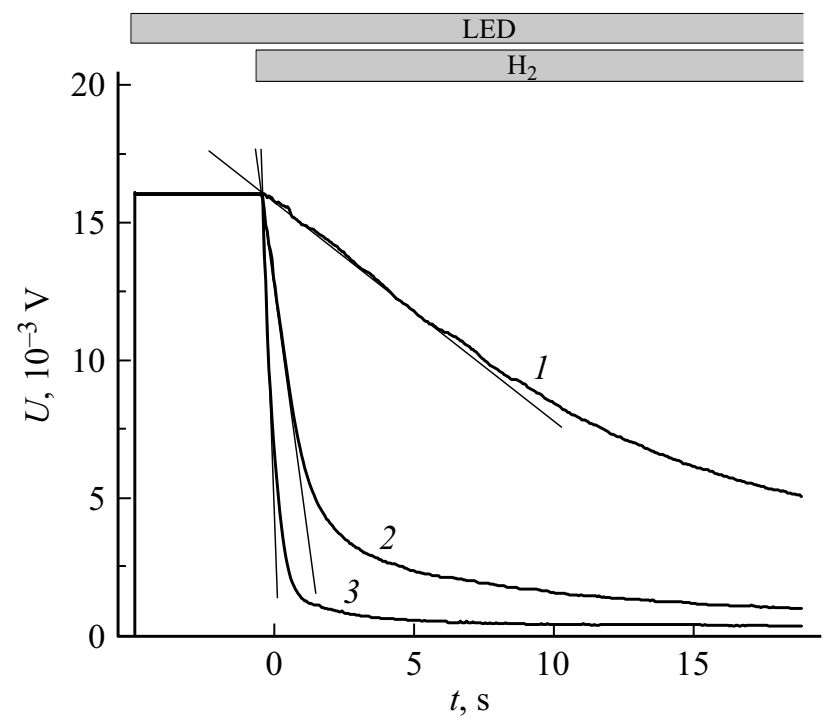

Рис. 2. Фотоэдс структуры $\mathrm{Pd}-$ оксид $-n-\operatorname{InP}$ при подаче на структуру газовой смеси с различным содержанием водорода, $N_{\mathrm{H}}$, об\%: $1-0.1,2-1.0,3-10.0$.

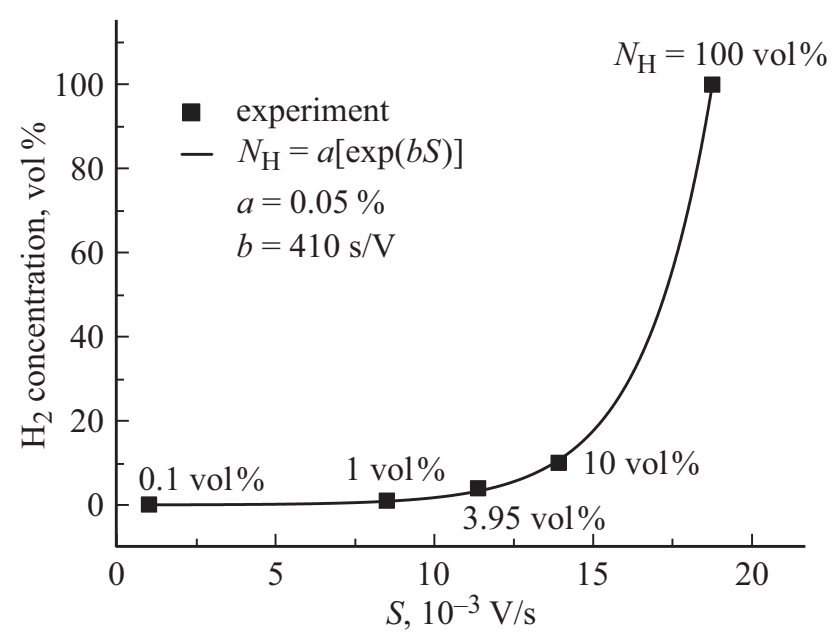

Рис. 3. Зависимость скорости спада фотоэдс структуры $\mathrm{Pd}-$ оксид $-n-\mathrm{InP}$ от концентрации водорода в газовой смеси. 


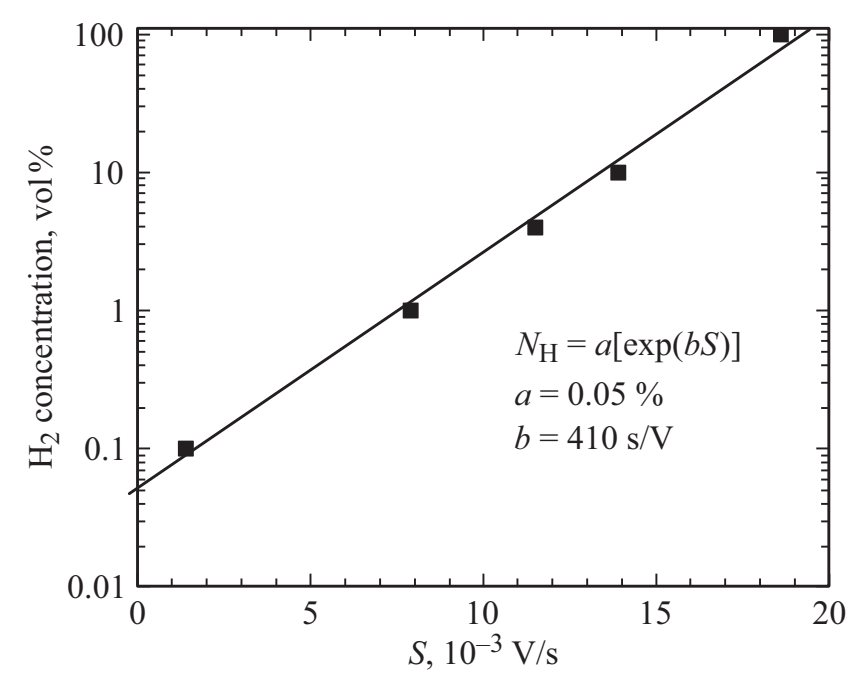

Pис. 4. Зависимость скорости спада фотоэдс в структуре $\mathrm{Pd}-$ оксид $-n$-InP от концентрации водорода в газовой смеси, построенная в полулогарифмических координатах.

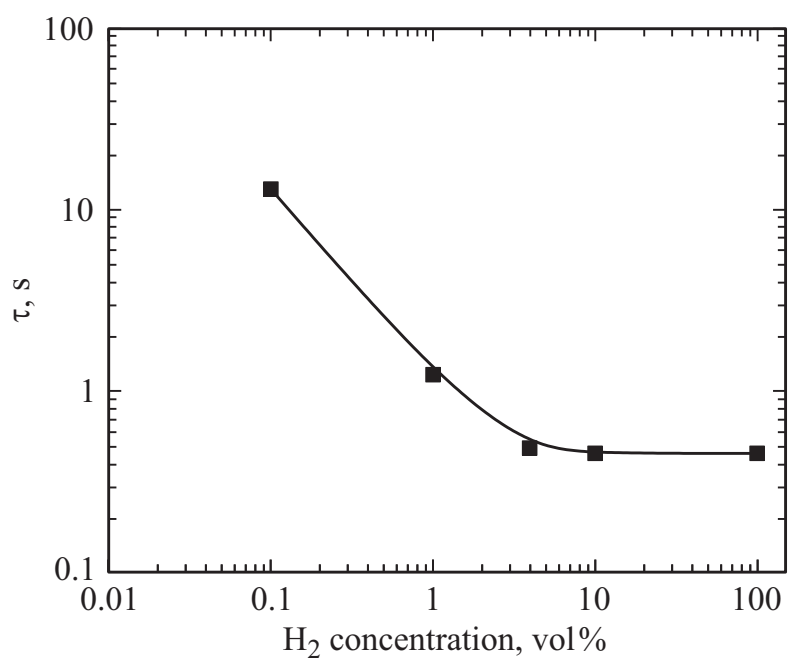

Рис. 5. Зависимость постоянной времени спада фотоэдс от концентрации водорода в окружающей среде для структур $\mathrm{Pd}-$ оксид $-n-\mathrm{InP}-$ характеристика быстродействия.

показал, что с увеличением концентрации водорода в газовой смеси увеличивается скорость спада фотоэдс. Отсюда следует, что по скорости спада фотоэдс можно количественно определить концентрацию водорода в газовой смеси. Эта экспериментально полученная корреляционная зависимость имеет экспоненциальный вид (рис. 3):

$$
N_{\mathrm{H}}=a \exp (b S)
$$

где: $N_{\mathrm{H}}-$ концентрация водорода в газовой смеси в об\%, $S=d U /\left.d t\right|_{t=0}$ - скорость изменения сигнала на начальном участке спада фотоэдс начиная с момента контакта структуры с газовой смесью, измеренная в В/c; для структуры $\mathrm{Pd}-$ оксид- $n$-InP постоянные в формуле равны: $a=0.05 \%, b=410 \mathrm{c} / \mathrm{B}$.
На рис. 4 представлена зависимость скорости спада фотоэдс в структуре $\mathrm{Pd}-$ оксид- $n$-InP от концентрации водорода в газовой смеси, построенная в полулогарифмических координатах. Аппроксимация зависимости прямой линией подтверждает экспоненциальный характер установленного закона.

Спад фотоэдс во времени (см. рис. 2) имеет неэкспоненциальное поведение. Если выполнить аппроксимацию экспериментальных кривых на начальном участке спада фотоэдс экспонентами, получим зависимость постоянной времени спада фотоэдс $(\tau)$ от концентрации водорода в газовой смеси. Данная постоянная времени характеризует быстроту реакции структуры на появление водорода в окружающей среде (рис. 5).

Полученный результат показывает, что на основе структур $\mathrm{Pd}-$ оксид- $n$-InP могут быть изготовлены сенсоры водорода с быстротой реакции $\sim 0.5$ с на появление взрывоопасной газовой среды, содержащей 3-100 об\% водорода.

\section{4. Заключение}

Результаты, представленные в данной работе, показывают, что на основе изготовленных по предложенной технологии структур $\mathrm{Pd}-$ оксид- $n$-InP могут быть созданы быстродействующие сенсоры водорода, способные работать при комнатных температурах, позволяющие количественно определять концентрацию водорода в окружающей газовой среде.

Авторы благодарят за полезные советы и помощь в изготовлении образцов МДП структур Н.Д. Ильинскую и А.А. Пивоварову.

\section{Список литературы}

[1] H.I. Chen, Y.I. Chou, C.Y. Chu. Sensors Actuators B, 85, 10 (2002).

[2] V.M. Aroutiounian. Int. Sci. J. Altern. Energy Ecol., N 3, 33 (2007).

[3] B. Podlepetsky, M. Nikiforova, A. Kovalenko. Sensors Actuators B, 254, 1200 (2018).

[4] P. Sun, Y. Yu, J. Xu, Y. Sun, J. Ma, G. Lu. Sensors Actuators $\mathrm{B}, 160$ (1), 244 (2011).

[5] Г.Г. Ковалевская, А.М. Маринова, С.В. Слободчиков. ЖТФ, 59 (11), 155 (1989).

[6] Х.М. Салихов. Автореф. докт. дис. (Санкт-Петербург, 2010).

[7] Е.А. Гребенщикова, В.В. Евстропов, Н.Д. Ильинская, Ю.С. Мельников, О.Ю. Серебренникова, В.Г. Сидоров, В.В. Шерстнев, Ю.П. Яковлев. ФТП, 49 (3), 376 (2015).

[8] А.Н. Именков, Е.А. Гребенщикова, В.А. Шутаев, А.М. Оспенников, В.В. Шерстнев, Ю.П. Яковлев. ФТП, 50 (7), 946 (2016).

[9] Е.А. Гребенщикова, В.А. Шутаев, А.А. Капралов. Патент РФ на изобретение № 2621879 от 07 июня 2017 г.

Редактор Л.В. Шаронова 


\title{
Determination of hydrogen concentration \\ by means of photovoltage of Pd-oxide-InP MIS structures
}

\author{
E.A. Grebenshchikova ${ }^{1}$, Kh.M. Salikhov', \\ V.G. Sidorov ${ }^{3}$, V.A. Shutaev ${ }^{1}$, Yu.P. Yakovlev ${ }^{1}$ \\ ${ }^{1}$ loffe Institute, \\ 194021 St. Petersburg, Russia \\ 2 The Institute for Applied Study, \\ Academy of Sciences of Tatarstan, \\ 420111 Kazan, Russia \\ ${ }^{3}$ IBSG Co., Ltd., \\ 194021 St. Petersburg, Russia
}

\begin{abstract}
Results are presented for photovoltage of a metalinsulator-semiconductor structure $(\mathrm{Pd}-$ oxide- $\mathrm{InP})$ versus hydrogen concentration in the range of $0.1-100 \mathrm{vol} \%$ in the nitrogen-hydrogen mixture. It is shown that under the simultaneous exposure of the $\mathrm{Pd}-$ oxide-InP structure by illumination and hydrogen the photovoltage drop speed and hydrogen concentration are connected with each other exponentially: $N_{\mathrm{H}}=a \exp (b S)$, where $N_{\mathrm{H}}-$ hydrogen concentration (vol\%) in nitrogen-hydrogen mixture, $S=d U /\left.d t\right|_{t=0}$ - speed of signal changing at the initial part of photovoltage decay, beginning from the moment when the structure interact with the gas mixture, $a$ and $b-$ constants depending on the thicknesses of oxide and Pd layers.
\end{abstract}

